\title{
EMOTIONAL INTELLIGENCE AND ACQUISITION OF ENGLISH LANGUAGE ORAL COMMUNICATION SKILLS
}

\author{
Tetiana Andrienko \\ Kyiv International University, Kyiv, Ukraine \\ tania_andrienko@gmail.com \\ Nataliia Chumak \\ Taras Shevchenko National University of Kyiv, Kyiv, Ukraine \\ nataliiachumak7@gmail.com \\ Vlad Genin \\ UOPX, Silicon Valley-Bay Area Campus, San Francisco, California, USA \\ vladgenin@yahoo.com
}

\begin{abstract}
Studying the factors of successful acquisition of ESL speaking skills in Ukrainian adult learners, the authors focused on the correlation between emotional intelligence and development of oral communication skills, and, on the other hand, on the growth of these indicators as a result of purposeful inclusion of content-related emotions into activities aimed at the development of speaking and listening skills. Theoretically based on the ideas of emotional intelligence as an important factor in human interaction and guided by the hypothesis that content-related emotions intensify emotional involvement and have a positive influence on the acquisition of oral communication skills, the researchers applied Mayer-Salovey-Caruso Emotional Intelligence Test and the English Language Oral Communication Skills Test developed by the authors, to measure the key oral communication skills indicators against a 100 point scale. Experimental teaching of 124 undergraduate students of International Relations during September 2018 - May 2019 proved a beneficial influence of including emotions in the learning activities on the acquisition of ESL oral communication skills, as well as on student motivation and overall quality of student experiences. Significant increments in Emotional Intelligence and ESL oral communication skills in the experimental group compared to insignificant growth of the same indicators in the Reference group allow to establish a positive correlation between the growth of emotional intelligence and acquisition of the ESL speaking skills pursuant to inclusion of content-related emotions into the ESL learning in Ukrainian students.
\end{abstract}

Keywords: emotional intelligence; ESL learning; oral communication skills; content-related emotions; adult education.

\section{Introduction}

Recent developments in psychology, pedagogical and andragogical studies prove that the results of learning activity do not solely depend on the students' intellectual potential and cognitive efforts, inferring the importance of studying the role of emotions in successful acquisition of required skills, in particular, in adult education. Specifically, mastering effective oral communication skills in a foreign language for adult learners majoring in International Relations is an important professional competence ensuring their ability to efficiently exert influences on the audience, persuade interlocutors, effectively negotiate etc. The role of emotional involvement, along with cognitive efforts, in learning a foreign language and acquisition of communication skills in that language, is of interest to teaching methodology, pedagogical and androgogical studies as well as to educational psychology.

Learning occurs when an individual has a relatively permanent change in behaviour, cognition, brain function, abilities or knowledge as a result of experiences. Over the past two decades, advances in neuroscience have revolutionised the way we think about the connection between learning, emotions and the brain. We now have extensive evidence that emotions and learning are inextricably connected (Panksepp, 1998; Immordino-Yang \& Damasio, 2007; Tyng et al., 2017; Estrada Guillén \& al., 2019).

It is undoubted that a person's emotional state greatly influences the effectiveness of learning. However, there is no agreement as to the type of influence emotions exert on learning. According to some reliable data, positive emotions aid learning while negative emotions prevent a person from learning effectively (Gutierrez \& al., 2017). On the other hand, it is not because an emotion is positive, in the broad sense, that will necessarily make it beneficial to the learning process. To be useful, it must be related to learning or a specific task; otherwise, it can impair attention and affect performance. In parallel - even if it is not a question of encouraging the rise of the learner's negative emotions - just because an emotion is negative, does not represent in all circumstances a brake for the learner. Anxiety, embarrassment or anger can motivate the learners to redouble their efforts, provided that the learners want to succeed and believe in their chances

Andrienko, T., Chumak, N., \& Genin, V. (2020). Emotional intelligence and acquisition of english language oral communication skills. Advanced Education, 15, 66-73. DOI: 10.20535/2410-8286.201013 
to thrive. Of course, the intensity and frequency of the negative emotion felt will also have an impact - if it is too strong or recurrent, the learner risks being overwhelmed by the feeling of helplessness (Meilleur, 2019).

Emotions such as enjoyment, anger, hope, pride and boredom, can each affect students' actions and learning in a variety of ways (Pekrun \& al., 2002; Rigoni \& al., 2015; Taheri \& al., 2019; Salavera \& al., 2020). These emotions can be affected by classroom factors (e.g., curriculum content, environment), individual differences between students (e.g., genetic factors, general tendencies), and external factors (e.g., social interactions, home environment) (Pekrun \& Linnenbrink-Garcia, 2014; Krishnakumar \& al., 2016; Trezise \& al., 2017).

For the purposes of this research, we believe it is necessary to discriminate between process-related emotions and content-related emotions. They should be studied separately, the former being the part of the learning process and social environment, and the latter - an intrinsic component and cognitive focus in the learning process. Our attention will be concentrated on the latter, i.e. emotions aroused by the content of education (learning texts and educational materials). According to our hypothesis, content-related emotions enhance the students' learning experience, motivation and oral communication skills. Our hypothesis is based on the idea of emotional intelligence as "the ability to perceive emotions, to access and generate emotions so as to assist thought, to understand emotions and emotional knowledge, and to reflectively regulate emotions so as to promote emotional and intellectual growth" (Mayer \& Salovey, 1997, p. 5). We suppose that involvement of the emotions in the course of learning/acquiring English language speaking skills by adult learners will not only enrich the learning experience and enhance memory and thinking (due to the interaction of 'cognitive' and 'emotional' brain zones), but also facilitate social interaction, communication skills and overall motivation of learners. The positive correlation of emotional intelligence quotient and successful acquisition of the English language has been revealed in a number of studies (Zarezadeh, 2013; Spirovska Tevdovska, 2017; Shakarami \& Khajehei, 2015; Genç \& al., 2016), but none of them focuses specifically on developing speaking skills.

Therefore, the aim of this research is to establish the influence of emotional intelligence (EI) on the acquisition and development of English-as-a-second language (ESL) oral communication skills in adult Ukrainian students. The research questions and the respective objectives are:

- to establish the correlation between emotional involvement through content-related emotions and acquisition of the ESL speaking skills;

- to observe the changes in EI pursuant to inclusion of content-related emotions into the ESL learning in Ukrainian students, and trace their correlation with the development of the ESL speaking skills.

\section{Methods}

\section{Research Design}

The research utilised a mixed methodology combining qualitative and quantitative data assessment. Quantitative methods involved Mayer-Salovey-Caruso Emotional Intelligence Test and the English Language Oral Communication Skills Test. Qualitative methods involved the analysis of students' learning experiences, motivation, involvement and overall satisfaction through interviews and opinion surveys.

\section{Participants}

It included 124 undergraduate Taras Shevchenko National University of Kyiv students majoring in International Relations, minoring in Translation (66 women and $58 \mathrm{men}$ ), English being their second language. The participants were divided into two groups - experimental and reference, equal in size (62 students each), approximately equal in academic achievements. All the students gave their informed consent to participate in the experiment.

\section{Instruments and Procedure}

The Research encompassed three stages: pre-experimental assessment, experiment and postexperimental assessment. Criteria of inclusion were: (1) Ukrainian being their native or first language (as the main language of instruction in the university); (2) the participants attended at least $90 \%$ of classes during the experiment.

At the pre-experimental assessment stage (September 2018) we measured the participants' levels of EI and English language oral communication skills (ELOCS) using the assessment methodology described below. During the experimental learning, all the subjects were given the assignments to present informative news (thematically relevant to their majors) to the audience of their peers with the subsequent discussion. The students in experimental group were instructed to render the news emotionally, trying to manifest 
through their presentation the feelings and emotions aroused by the events discussed in the news (e.g., to manifest excitement, admiration, pride while reporting victories and achievements; to express sorrow, grief and condolence while reporting sad or tragic news). The audience was instructed to perceive and understand the speaker's emotions and react by expressing their own emotional attitude. The students in the reference group were given no specific instructions as to emotionality of presentation. At the post-experimental assessment stage (May 2019) the participants' levels of EI and ELOCS were measured again using the same methodology. The results were interpreted and discussed to formulate the conclusion and recommendations as to the influence of emotional intelligence on the oral communication learning.

Data Analysis

The participants were assessed in two aspects, with the aim of establishing the correlation between them.

Emotional Intelligence was measured following the procedures of Mayer-Salovey-Caruso Emotional Intelligence Test (MSCEIT) which measures EI under four rubrics ('Four Branches of Emotional Intelligence':

- Perceiving emotions: the ability to perceive emotions in oneself and others as well as in objects, art, stories, music, and other stimuli

- Facilitating thought: the ability to generate, use, and feel the emotion as necessary to communicate feelings or employ them in other cognitive processes

- Understanding emotions: the ability to understand emotional information, to understand how emotions combine and progress through relationship transitions, and to appreciate such emotional meanings

- Managing emotions: the ability to be open to feelings, and to modulate them in oneself and others so as to promote personal understanding and growth (Mayer, Salovey \& Caruso, 2002;

Brackett \& Salovey, 2006; Rivers \& al., 2007).

The MSCEIT scores were reported so that the average score is 100 and the standard deviation is 15 . If a person obtains a MSCEIT score around 100, then they are in the average range of emotional intelligence ('Competent'), measuring EI against a normative scale (Mayer, Salovey \& Caruso, 2002, p. 71). The results beyond standard deviation were classified respectively: 115 and above as 'Skillful' and 84 and below as 'Consider development'.

ESL oral communication skills were assessed using the set of criteria to measure (1) the Speaker's performance, (2) the Hearers' reactions.

Criteria for measuring the Speaker's performance included quantitative and qualitative parameters.

Quantitative parameters:

- length of speech,

- length of sentences/phrases,

- number of words naming emotions,

- number of emotionally marked words,

- $\quad$ number of emotionally marked sentence patterns.

Qualitative parameters:

- relevance of emotion,

- relevance of degree of emotion,

- expressiveness of mimics, gestures, non-verbal communication tools,

- $\quad$ appeal to the audience (eye-contact, intonation),

- adequateness of role performance.

Criteria for measuring the Hearers' reactions also included quantitative and qualitative parameters.

Quantitative parameters:

- number and readiness of reactions,

- length of sentences/phrases,

- number of words naming emotions,

- number of emotionally marked words,

- number of emotionally marked sentence patterns.

Qualitative parameters:

- emotional engagement while listening,

- relevance of reactions to the topic,

- relevance of emotional response,

- expressiveness of mimics, gestures, non-verbal communication tools,

- ability to manage emotional dissonance. 
Each criterion was assessed according to a 10-point scale (0 indicating the absence or minimal possible level, and 10 indicating the maximal possible level of manifestation of a certain parameter), the overall top indices both for the Speaker's performance and for the Hearers' reactions being 100. While the quantitative parameters were registered by the researcher, the qualitative data were obtained by surveying the audience through standardised questionnaires. The individual assessment indices were then arithmetically averaged, respectively, for the Experimental Group and Reference Group. In comparative assessment, differences of 15 points $(15 \%)$ and above were considered significant.

\section{Results}

For the ESL learners, an essential problem in measuring and developing their EI may be the lack of knowledge of the words naming emotions, therefore before the EI assessment, the students of all the groups learned and discussed the names of positive and negative emotions. Though debate still exists regarding the categorisation of emotions, Robinson (2009), based on a wide review of current theories, presented a table of 11 pairs of basic positive and negative emotions, categorised into six kinds of emotion (Robinson, 2009) (Table 1).

Table 1. Names of basic positive and negative emotions (quoted from: Robinson, 2009)

\begin{tabular}{|l|l|l|}
\hline Kind of Emotion & \multicolumn{1}{|c|}{ Positive Emotions } & \multicolumn{1}{|c|}{ Negative Emotions } \\
\hline $\begin{array}{l}\text { Emotions related to object } \\
\text { properties }\end{array}$ & $\begin{array}{l}\text { Interest, curiosity, } \\
\text { enthusiasm }\end{array}$ & Indifference, habituation, boredom \\
\hline & $\begin{array}{l}\text { Attraction, desire, } \\
\text { admiration }\end{array}$ & Aversion, disgust, revulsion \\
\hline & Surprise, amusement & Alarm, panic \\
\hline Future appraisal emotions & Hope, excitement & Fear, anxiety, dread \\
\hline Event-related emotions & Gratitude, thankfulness & Anger, rage \\
\hline & $\begin{array}{l}\text { Joy, elation, triumph, } \\
\text { jubilation }\end{array}$ & Sorrow, grief \\
\hline Self-appraisal emotions & Patience & Frustration, disappointment \\
\hline Social emotions & Contentment & Discontentment, restlessness \\
\hline & Humility, modesty & $\begin{array}{l}\text { Pride, thinking or acting in a way above } \\
\text { others }\end{array}$ \\
\hline Cathected emotions & Charity & $\begin{array}{l}\text { Avarice, greed, miserliness, envy, } \\
\text { jealousy }\end{array}$ \\
\hline & Sympathy & Cruelty \\
\hline & Love & Hate \\
\hline
\end{tabular}

Emotional Intelligence. The MSCEIT test which is based on an ability model of emotional intelligence, was used in the English language version (because of the students' advance level of English) to measure the participants' potential EI. Before the experimental learning, the arithmetic mean for the Experimental Group was 102, and for the Reference Group 106, both indicators being within the standard deviation interval from average (i.e., 'competent'). After the experimental learning, the same methodology and procedures resulted in establishing the arithmetic mean in the Experimental Group equal to 126, which is significantly above average (and classified as 'skilful'). For the Reference Group, the arithmetic mean EI was 112, which is within the standard deviation interval from average (i.e., 'competent').

This shows that before the experimental learning the average EI in Experimental and Reference groups were statistically the same, while after the experimental learning focused on expressing and perceiving emotions, the average EI in the Experimental Group was significantly higher than in the Reference Group as well as in the Experimental Group before the experimental learning (Table 2).

Table 2. Pre-experimental and Post-experimental Emotional Intelligence Indicator

\begin{tabular}{|l|c|c|}
\hline Emotional Intelligence Indicator & Pre-experimental & Post-experimental \\
\hline Experimental Group & $\mathbf{1 0 2}$ & $\mathbf{1 2 6}$ \\
\hline Reference Group & 106 & 112 \\
\hline
\end{tabular}


Comparative growth of Emotional Intelligence Indicator in the Experimental and Reference groups as the result of experimental learning proves a positive effect of including content-related emotions into the learning process in the Experimental Group, which is shown schematically on Fig. 1. A deliberate focus on perceiving the speaker's emotions, correlating them with cognitive information, generating an emotional response, managing emotions, in particular, in the case of dissonance, enhanced the overall emotional and social competence of the adult learners, creating a foundation for the development of professionally relevant features and skills, such as emotional compassion, emotional influence, negotiating, managing conflict, etc.

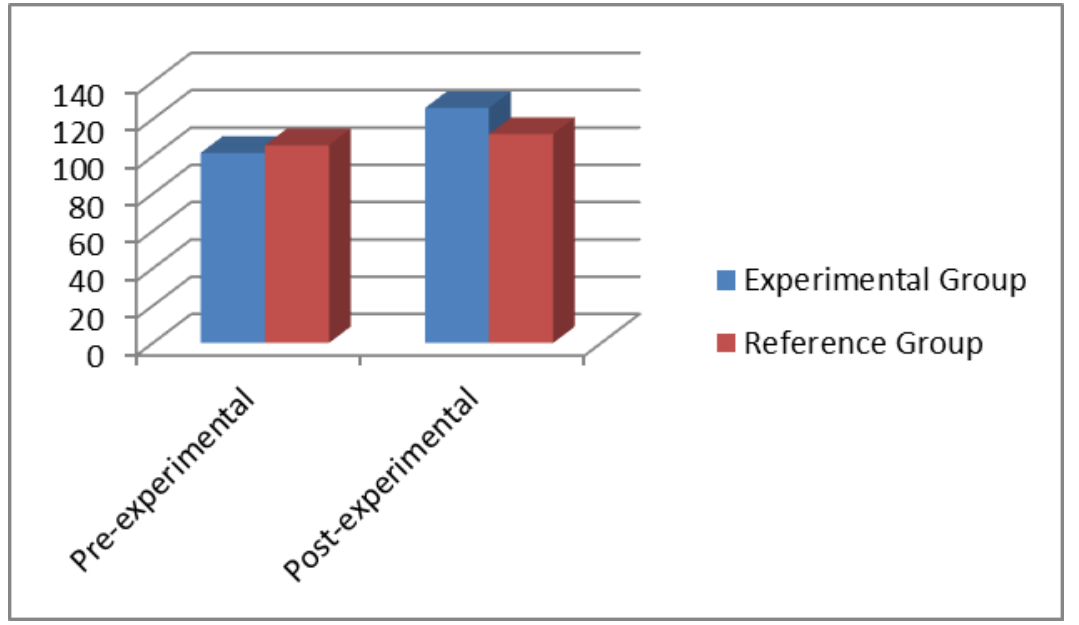

Fig.1. Comparative growth of Emotional Intelligence Indicator

English-as-a-second language oral communication skills assessment at the pre-experimental stage was performed in all groups during September 2018 and indicated the following results for the Speaker's performance: in the Experimental Group - 54, and for the Reference Group - 56. The Hearers' reactions indicators at the pre-experimental stage were: in the Experimental Group - 48, and for the Reference Group - 42. After the experimental learning (May 2019) in the Experimental Group, we observed a significant increase in the Speaker's performance - up to 78, in the Reference Group this indicator increased to 68, which is within $15 \%$. The Hearers' reactions indicators also grew significantly in the Experimental Group and reached at the post-experimental stage 86, while for the Reference Group the increase was not significant - to 52 (Table 3).

Table 3. Pre-experimental and Post-experimental English Language Oral Communication Skills Indicator

\begin{tabular}{|c|c|c|}
\hline $\begin{array}{c}\text { English Language Oral } \\
\text { Communication Skills Indicator }\end{array}$ & Pre-experimental & Post-experimental \\
\hline \multicolumn{3}{|c|}{ Experimental Group } \\
\hline Speaker's Performance & 54 & 78 \\
\hline Hearers' Reactions & 48 & 86 \\
\hline Speaker's Performance & 56 & 68 \\
\hline Hearers' Reactions & 42 & 52 \\
\hline
\end{tabular}

Comparative growth of the ELOCS Indicator in the Experimental and Reference groups shows that the experimental learning focused on emotional involvement led to the enrichment of the learners' language emotional 'tools': better knowledge and more frequent usage of words naming emotions, emotional words and sentence models, greater expressiveness of intonation. Essential progress was observed both in speaking / presentation skills and listening and participation in discussion. This shows the overall growth of ESL oral communication skills development above the level of the Reference Group where the students were taught according to traditional methodology and no specific attention was dedicated to emotions and their role in communication. The growth of ELOCS indicators in the Experimental and Reference groups is shown schematically on Fig. 2. 


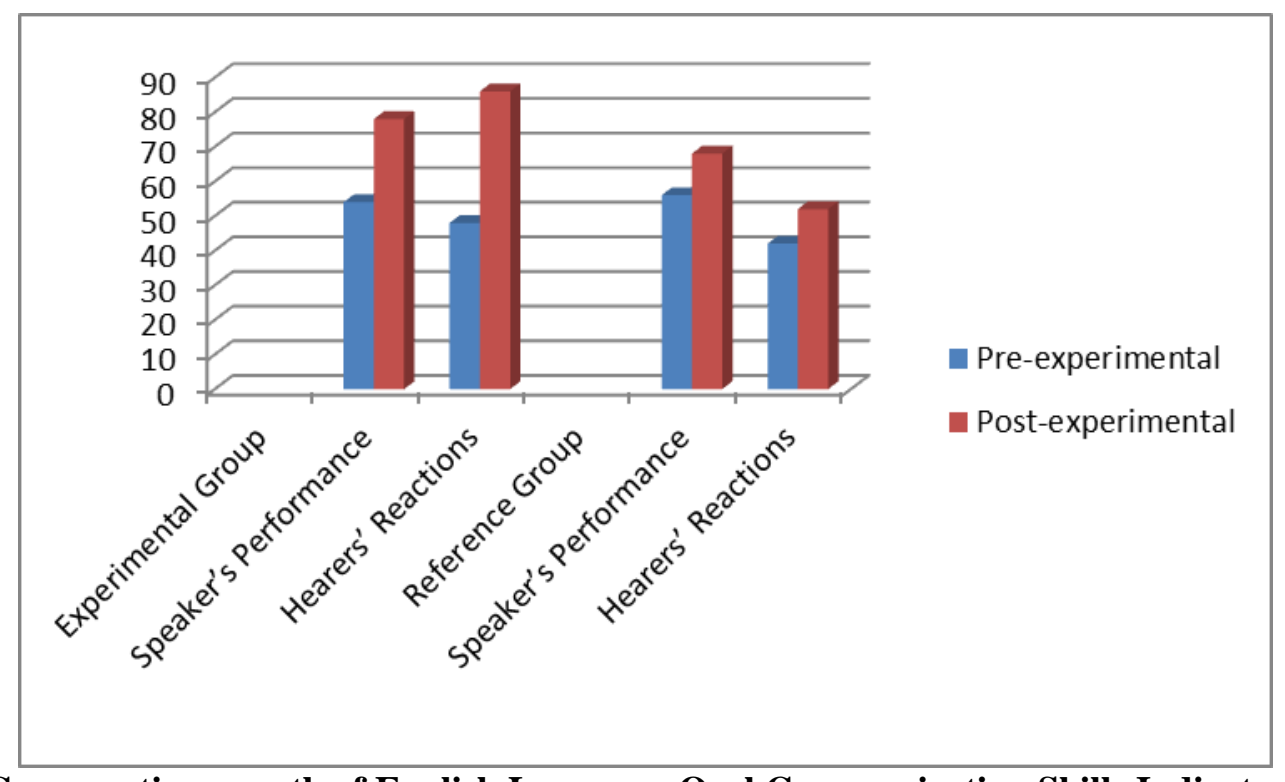

Fig.2. Comparative growth of English Language Oral Communication Skills Indicator

\section{Discussion}

The association between emotions and cognitive function is undeniable and has a physiological ground. Emotions originate in the limbic system of the brain. The nuclei and cortical structures of the limbic system regulate autonomic and endocrine function, particularly in response to emotional stimuli. They set the level of arousal and are involved in motivation and reinforcing behaviours. Additionally, many of these areas are critical to particular types of memory (Swenson, 2006). So memory, an important component of learning, involves the limbic system which is located in the middle of the brain between the lower centre or brainstem and the higher centre or cortex. The brainstem controls alertness and arousal and sends sensory messages to the cortex via the limbic system. Much of our thinking and learning takes place in the cortex. Thus, the old view that emotions interfere with learning is being replaced by the new view that emotions and cognition are supported by interdependent neural processes. The very large interdependence [overlap] between emotion and cognition is termed "emotional thought" and encompasses processes of learning, memory, decision-making, and creativity (Immordino-Yang \& Damasico, 2007). Emotions regulate and often underlie most essentially cognitive activities. "It is literally neurobiologically impossible to build memories, engage complex thoughts, or make meaningful decisions without emotions" (Immordino-Yang, 2016).

However, scholarly opinions as to impacts of positive and negative emotions on learning differ. Some researchers prove that happiness has a positive effect on learning, memory and social behaviour (Hernik \& Jaworska, 2018). Conversely, "negative emotions are held to be detrimental to the pursuit of achievement goals, investment of effort, cognitive processes (such as attention and memory), motivation, self-regulation and self-efficacy" (Rowe \& Fitness, 2018). On the other hand, stress, a negative emotional state, has been reported to facilitate and/or impair both learning and memory, depending on intensity and duration (Vogel \& Schwabe, 2016; Tyng et al., 2017). More specifically, mild and acute stress facilitates learning and cognitive performance, while excess and chronic stress impairs learning and is detrimental to memory performance (Tyng et al., 2017). Emotional roles are particularly important in the process of encoding new information containing emotional components. The latter increases attention toward salient new information by selectively enhancing detection, evaluation, and extraction of data for memorisation (Tyng et al., 2017).

A shrewd insight is provided by Immordino-Yang's metaphorical representation of correlation between emotions and cognitive processes: prior to the findings of affective social neuroscience research, "emotions were [viewed] like toddlers in a china shop, interfering with the orderly rows of stemware [cognition] on the shelves", however, based on evidence from patients with brain damage, as well as from healthy people, the view has dramatically changed, "taken as a whole, [research studies] show that emotions are not just messy toddlers in a China shop, running around breaking and obscuring delicate cognitive glassware. Instead, [emotions] are more like the shelves underlying the glassware; without them cognition has less support" (Immordino-Yang, 2016, p. 32). As the comparison prompts, the positive impact of emotions on learning is not so much determined by a positive/negative nature of the emotion, but rather by the individual's ability to manage their emotions: to perceive, understand and modify their own emotional state, to empathise or transform the others' emotions. Such ability, encompassed by the concept of emotional intelligence, was compared in our study to language (speaking skills) learning ability and showed a positive correlation. 
The growth of average EI in the Experimental Group from 'competent' (102) to 'skilful' (126) resulted from a focus on emotional attitudes to events and objects described in the learning materials (texts of the news to be presented in class). This required the students to (1) evaluate a certain event and give it an emotional interpretation, (2) develop their ability to express emotions and excite an emotional state in their audience, (3) to perceive and interpret other people's emotions, (4) to manage emotionality, in particular emotional dissonance. The same focus on the emotional treatment of the events resulted in better memorising names of emotions and emotionally marked words and emotionally marked syntactic models, which all grew significantly both in speakers' performances (from 54 to 78) and hearers' reactions (from 48 to 86 ). Our results resonate with the conclusions by Immordino-Yang (2016), Schmidt (2017), Esmaeeli et al (2018): "we only think deeply about the things we care about" (Immordino-Yang 2016, p. 18). Helping students attend to what they are learning is difficult and complex as well as helping them to emotionally connect with the thinking of the discipline is a whole different level of connectedness (Schmidt, 2017), but all that "appears to be essential for the development of truly useful, transferable, intrinsically motivated learning" (Immordino-Yang 2016, p. 20).

In the Reference Group which learned the same programme material, but without a specific focus on emotions and emotional interaction, we observed the increase in EI which was not significant as it was within 15\% standard deviation interval. The growth of speaker's performance indicator (from 56 to 68) was observed as the result of the students' overall progress in learning the English language speaking skills (longer and more complicated sentences etc.); however, it was not significant in terms of emotionality. Similarly, the growth in hearers' reactions (from 42 to 52) was not significant.

\section{Limitations}

As with the majority of studies, the findings of the current research are subject to certain limitations. The sampling for inclusion into the Experimental and Reference groups disregarded gender differences as well as differences in the students' specialisations (Law, Business, Culture Studies) which by themselves may influence the level of the participants' emotiveness. Additionally, the students' awareness of their participation in the experiment might by itself increase their interest and motivation. While the former limitations may comprise a subject of furthermore specialised studies, the latter may only be overcome by a blind design of research which implies not informing the students of their participation in the research.

\section{Conclusions}

Our study clearly shows the growth of Emotional Intelligence and English-as-a-second language oral communication skills as a result of inclusion into the learning process of content-related emotions. The established positive correlation between EI and ELOCS proves the intensifying and amplifying effect of content-related emotions on memory and cognitive function of adult learners. In the course of the experiment, we also observed the growth of student's interest and involvement in the discussions, their positive motivation and better learning student experiences.

The new and evolving understanding of the intimate connection between emotion and cognition leads to a myriad of insights that have the potential to inform and transform educational practices at all levels - from the classroom to the curriculum to educational policy. Further prospects of this research include studying the role of emotional involvement in online (with audiovisual aid) and hybrid modalities which become more and more popular with the development of more sophisticated educational platforms and globalisation of education. Emotional involvement and emotional intelligence in developing oral communicational skills is a path towards further enhancement of language teaching results and learning outcomes in both online and hybrid modalities.

\section{References:}

Brackett, M.A. \& Salovey, P. (2006) Measuring emotional intelligence with the Mayer-Salovey-Caruso Emotional Intelligence Test (MSCEIT). Psicothema, 18, 34-41. Retrieved 20 February from https://psycnet.apa.org/record/2006-12699-005

Esmaeeli Zohre, Masoud Khalili Sabet and Yadollah Shahabi (2018). The Relationship between Emotional Intelligence and Speaking Skills of Iranian Advanced EFL Learners. International Journal of Applied Linguistics \& English Literature, 7(5), 22-28. http://dx.doi.org/10.7575/aiac.ijalel.v.7n.5p.22

Estrada, M., Monferrer, D., \& Moliner, M.A. (2019). The Relation between Learning Styles according to the Whole Brain Model and Emotional Intelligence: A Study of University Students. Estudios Sobre Educacion, 26, 85-111. https://doi.org/10.15581/004.36.85-111

Genç G., Kuluşaklı E., Aydın, S. (2016). The Relationship between Emotional Intelligence and Productive Language Skills. The Reading Matrix: An International Online Journal, 16, 91-105. Retrieved 2 March from http://www.readingmatrix.com/files/14-za822316.pdf

Gutierrez, D., Mullen, P.R., \& Fox, J. (2017). Exploring Emotional Intelligence Among Master's-Level Counseling Trainees. Counselor Education and Supervision, 56(1), 19-32. https://doi.org/10.1002/ceas.12057 
Hernik, J. \& Jaworska, E. (2018). The effect of enjoyment on learning. http://doi.org/10.21125/inted.2018.1087

Immordino-Yang, M. H. (2016). Why emotions are integral to learning? Retrieved 10 March from https://www.kqed.org/mindshift/45201/why-emotions-are-integral-to-learning

Immordino-Yang, M.H., Damasico, A.R. (2007). We feel, therefore, we learn: The relevance of affective and social neuroscience to education. Mind, Brain, and Education, 1(1), 3-10. https://doi.org/10.1111/j.1751-228X.2007.00004.x

Krishnakumar, S., Hopkins, K., Szmerekovsky, J., \& Robinson, M.D. (2016). Assessing Workplace Emotional Intelligence: Development and Validation of an Ability-based Measure. The Journal of Psychology Interdisciplinary and Applied, 150 (3), 371-404. https://doi.org/10.1080/00223980.2015.1057096

Mayer, J.D. \& Salovey, P. (1997). What is Emotional Intelligence? In P.Salovey \& D.J. Sluyter (Eds.), Emotional Development and Emotional Intelligence: Educational Implications (pp.3-34). New York : BasicBooks; Harper Collins Publishers. Retrieved 2 March from https://psycnet.apa.org/record/1997-08644-000

Mayer, J.D., Salovey, P., \& Caruso, D. (2002). Mayer-Salovey-Caruso Emotional Intelligence Test (MSCEIT). Toronto, Ontario: Multi-Health Systems, Inc. Retrieved 2 March from https://mypages.unh.edu/jdmayer/mayer-salovey-caruso-emotionalintelligence-test-msceit

Mayer, J.D., Salovey, P. \& Caruso, D.R. (2008). Emotional Intelligence: New Ability or Eclectic Traits? American Psycologist, 63 (6), 503-517. https://doi.org/10.1037/0003-066X.63.6.503

Meilleur, C. (2019). The Importance of Emotions in Learning. Knowledge One. Retrieved 3 March from https://knowledgeone.ca/indepth-analysis-the-importance-of-emotions-in-learning/

Panksepp, J. (1998). Affective Neuroscience: The Foundations of Human and Animal Emotions. Oxford: Oxford university press. Retrieved 2 March from https://books.google.com.ua/books/about/Affective_Neuroscience.html?id=qqcRGagyEuA C\&redir_esc $=$ y

Pekrun, R. \& Linnenbrink-Garcia, L. (2014). International Handbook of Emotions in Education. NY \& London : Routledge. https://doi.org/10.4324/9780203148211

Pekrun, R., Goetz, T., Titz, W. \& Perry, R.P. (2002). Academic Emotions in Students' Self-Regulated Learning and Achievent: A Program of Qualitative and Quantitative Research. Educational Psychologist, 37 (2), 91-105. https://doi.org/10.1207/S15326985EP3702_4

Rigoni, D., Demanet, J. \& Sartori, G. (2015). Happiness in action: the impact of positive affect on the time of the conscious intention to act. Frontiers in Psychology, 6, 1307. https://doi.org/10.3389/fpsyg.2015.01307

Rivers, S.E., Brackett, M.A., Salovey, P. \& Mayer, J.D. (2007). Measuring Emotional Intelligence as a set of mental abilities. In G. Matthews, M. Zeidner, \& R. D. Roberts (Eds.), The science of emotional intelligence: Knowns and unknowns (pp. 231257). Oxford University Press. Retrieved 4 March from https://psycnet.apa.org/record/2007-12449-009

Robinson, D.L. (2009). Brain function, mental experience and personality. The Netherlands Journal of Psychology, 64, $152-67$. https://doi.org/10.1007/BF03076418

Rowe, A.D. \& Fitness, J. (2018). Understanding the Role of Negative Emotions in Adult Learning and Achievement: A Social Functional Perspective. Behavioral Sciences, 8(2), 27. https://doi.org/10.3390/bs8020027

Salavera, C., Usán, P., Teruel, P., \& Antoñanzas, J.L. (2020). Eudaimonic Well-Being in Adolescents: The Role of Trait Emotional Intelligence and Personality. Sustainability, 12 (7), 2742. https://doi.org/10.3390/su12072742

Schmidt, S.J. (2017). What Does Emotion Have to Do with Learning? Everything! Journal of Food Science Education, 16(3), 64-66. https://doi.org/10.1111/1541-4329.12116

Shakarami, A. \& Khajehei, H. (2015). How Emotional Intelligence and Language Learning Strategies Interact in an EFL Setting. International Journal of Applied Linguistics \& English Literature, 4 (2). https://doi.org/10.7575/aiac.ijalel.v.4n.2p.229

Spirovska Tevdovska, E. (2017). The Impact of Emotional Intelligence in the Context of Language Learning and Teaching. SEEU Review, 12(1). https://doi.org/10.1515/seeur-2017-0009

Swenson, R.S. (2006) Review of clinical and functional neuroscience Retrieved 5 March from https://www.dartmouth.edu/ rswenson/NeuroSci/chapter_9.html

Taheri, H., Bagheri, M., Sadighi, F., \& Bavali, M. (2019). EFL learners' L2 achievement and its relationship with cognitive intelligence, emotional intelligence, learning styles, and language learning strategies. Cogent Education, 6. https://doi.org/10.1080/2331186X.2019.1655882

Tresize, K., Bourgeois, A. \& Luck, C. (2017). Emotions in classroom: The need to understanf how emotions affect learning and education. NPJ Science of Learning. Retrieved 6 March from https://npjscilearncommunity.nature.com/users/53799-kellytrezise/posts/18507-emotions-in-classrooms-the-need-to-understand-how-emotions-affect-learning-and-education

Tyng, C.M, Amin, H.U., Saad, M.N.M., \& Malik, A.S. (2017).The Influences of Emotion on Learning and Memory. Frontiers of Psychology, 8, 1454. https://doi.org/10.3389/fpsyg.2017.01454

Vogel, S. \& Schwabe, L. (2016). Learning and memory under stress: implications for the classroom. Sci. Learn, 1, 1-10 https://doi.org/10.1038/npjscilearn.2016.11

Zarezadeh, T. (2013). The effect of emotional intelligence in English language learning. Procedia - Social and Behavioral Sciences, 84, 1286-1289. https://doi.org/10.1016/j.sbspro.2013.06.745 